\title{
Cultivation of Oyster Mushroom (Pleurotus ostreatus) from Agro-waste and Dry Leaf Litter in used Plastic Bottles: Community Waste Management Model Targeting Stubble and Dry Leaf Burning
}

\author{
Sandeep Kaur (D), Himanshi Bansal (D), Bahaar Hundal (D), Bhavya Arora (D), \\ Navneet Kaur (D), Nikita Sharma (D) and Vandana Sharma \\ Department of Food Science, Mehr Chand Mahajan DAV College for Women, Chandigarh - 160 036, India.
}

\begin{abstract}
In recent years, solid waste management has developed from early approaches of burning or dumping to reuse, recycle, regain, and retain various alternative technologies. The present study aims at developing an effective community waste management model with a solution to multiple issues. It aims to provide an alternative to widespread stubble burning, burning dry leaf litter and promoting plastic reuse. The present novel technology involved the cultivation of Oyster Mushroom (Pleurotus ostreatus) in used plastic bottles to convert agricultural and urban waste into a highly nutritional end product. In this direction, the effect of different wheat straw and dry leaves' ratios was assessed on the spawn run time, primordial formation, final harvesting time, mean yield per plastic bottle, and the \% biological efficiency per gram of the substrate. Both the combinations of $L_{30}: W S_{70}$ and $L_{50}: W S_{50}$ represented ideal options for using the two waste substrates to cultivate the mushroom species. This model will help recycle agro-waste and serve as an effective method of generating nutritious food for fighting food security while decreasing the plastic load and trash thrown for disposal.
\end{abstract}

Keywords: Oyster mushroom, Pleurotus ostreatus, Biological Efficiency, Plastic bottles, Dry leaves, Stubble burning

*Correspondence: vandanamcm5@gmail.com

(Received: February 03, 2021; accepted: March 24, 2021)

Citation: Kaur S, Bansal H, Hundal B et al. Cultivation of Oyster Mushroom (Pleurotus ostreatus) from Agro-waste and Dry Leaf Litter in used Plastic Bottles: Community Waste Management Model Targeting Stubble and Dry Leaf Burning. J Pure Appl Microbiol. 2021;15(2):639-649. doi: 10.22207/JPAM.15.2.07

(C) The Author(s) 2021. Open Access. This article is distributed under the terms of the Creative Commons Attribution 4.0 International License which permits unrestricted use, sharing, distribution, and reproduction in any medium, provided you give appropriate credit to the original author(s) and the source, provide a link to the Creative Commons license, and indicate if changes were made. 


\section{INTRODUCTION}

Plastic is everywhere. Its cheapness, durability, and versatility have made our lives very easy and is used on a large scale worldwide. However, the biggest challenge is the fact that plastic degradation is a pressing issue as plastic never really goes away, it just breaks into microscopic pieces of plastic lying in a nonbiodegradable state ${ }^{1}$. Similar to the plastic menace is the rising issue of burning agricultural waste. It has been estimated that a total of $80-90 \%$ of generated agricultural biomass, i.e. paddy and wheat straw, is burned annually. This burning of used agricultural waste residues, also referred to as Crop Residue Burning (CRB), represents a major health hazard adding to increased levels of Particulate Matter (PM) concentration in the immediate vicinity ${ }^{2}$, thus posing a detrimental effect on human, animal and plant health. It has also become a major source of pollution in and around Punjab and Haryana, contributing between 12 and 60 per cent of PM levels in the surrounding $\mathrm{air}^{3}$. Therefore, the alternative need for utilising the agricultural waste residues is the need of the hour. Another major challenge in front of local government bodies is the disposal of huge heaps of dry leaves collected by the cleaning staff daily that can be seen lying unattended all over various city roads. The leaves are put on fire, leading to heavy smoke and air pollution, making life especially worse for asthmatics, children, elderly, pregnant women, chronic respiratory disease patients, etc. As per the Municipal Solid Wastes (Management and Handling) Rules, 2000, which came into effect in 2001, the burning of dry leaves is prohibited and is a punishable offence ${ }^{4}$. However, sadly the practice of burning leaves continues. This calls for newer and more effective scientific ways to tackle the situation rather than burning them.

With solid waste management as the main objective, the present study was focused on the management of agro-waste and green waste by using it as a potential substrate for the growth of a highly nutritious variety of mushrooms, i.e. oyster mushrooms in used plastic bottles. Oyster mushrooms are loaded with an array of culinary, medicinal, nutritional and environmental benefits. Besides providing both macro and micro-nutrition, they help maintain a strong immunity, maintain healthy bones, have proven anti-cancer, anti- diabetic and cholesterol-lowering potential ${ }^{5-8}$. Considering the availability of vast amounts of agro-waste and dry leaves and the pressing need to re-use and reduce plastic waste, this study proposes and promotes the cultivation of oyster mushroom from a mix of agricultural and green waste as an effective method of generating nutritious food serving multiple purposes of fighting food security, generating employment and a step towards decreasing the plastic load and trash thrown for disposal.

\section{MATERIAL AND METHODS \\ Culture Source}

The pure culture of Pleurotus ostreatus was obtained from Punjab Agricultural University, Ludhiana.

\section{Pure Culture Identification and Maintenance}

The pure culture of $P$. ostreatus so obtained were then transferred onto Potato dextrose agar plates (PDA) and slants. The cultures were later authenticated by microscopic and macroscopic features and stored at $4^{\circ} \mathrm{C}$ for later experimentation and future use.

\section{Production of Spawn}

Wheat was used for spawn preparation. Wheat grains were procured from the local grain market, thoroughly washed and then soaked in water overnight. The next day, the moisture content of grains reached approximately $50-60 \%$, and the water was allowed to drain off as the grains were made water-free. Spawn substrate was formulated by mixing wheat grains with $1 \%$ gypsum. The formulated substrate was finally packed in sterile glass jars occupying $75 \%$ of the space within the jar. This was followed by autoclaving the filled jars at $121^{\circ} \mathrm{C}$ and $15 \mathrm{psi}$ for $1 \mathrm{~h}$. After autoclaving, the jars were allowed to cool to room temperature and were ready to be inoculated. Inoculation of the spawn substrate within the glass jars was done by aseptically transferring seven-day fungal cultures sliced using sterile scalpels. Afterwards, the jars were incubated at ambient temperature and regularly observed at an interval of 48-72 $\mathrm{h}$ until the grains became fully colonised by mycelia turning white (cottony) in the jars.

\section{Substrate Preparation}

Wheat straw was obtained locally from the village area surroundings of Manimajra and 
Hallomajra. Dry garden leaves were procured from huge heaps collected near the road side in and around sector 36 , sector 37,38 and college garden areas. These substrates were manually cleaned with running tap water 3-4 times to remove dirt and grit particles. The leaves were then manually cut into smaller pieces and soaked overnight in clean tap water. Similarly, washed wheat straw was also separately soaked in water overnight to

Table 1. Different combinations of substrates used for spawning

\begin{tabular}{|c|c|c|}
\hline S.No. & Combination & Ratio \\
\hline 1. & Only wheat (WS) & 100 \\
\hline 2. & Leaves + wheat straw & \\
\hline 3. & $\begin{array}{l}\left(L_{30}-W S_{70}\right) \\
\text { Leaves + wheat straw }\end{array}$ & $30: 70$ \\
\hline 4. & $\begin{array}{l}\left(\mathrm{L}_{50}-\mathrm{WS}_{50}\right) \\
\text { Leaves+ wheat straw }\end{array}$ & $50: 50$ \\
\hline & $\left(\mathrm{L}_{70}-\mathrm{WS}_{30}\right)$ & $70: 30$ \\
\hline 5. & Only leaves (L) & 100 \\
\hline
\end{tabular}

moisten. The next day, water was drained out, and the substrates were allowed to dry for another 24 h. The dried substrates' moisture was checked by making a lump of the substrates as it should not form a self-assembled lump. All the substrates were then filled in high-density polyethylene bags and autoclaved at $121^{\circ} \mathrm{C}$ and $15 \mathrm{psi}$ for $30 \mathrm{~min}$. The autoclaved bags were then allowed to cool to room temperature before final mixing.

\section{Cleaning and Disinfection of Plastic Bottles}

Different one time used bottles (Bisleri bottles) were collected from the college canteen. They were thoroughly cleaned and washed 3-4 times with soap and running tap water. After washing, bottles were disinfected by dipping in $6 \%$ sodium hypochlorite solution overnight. The next day, bottles were washed twice with distilled water to remove the disinfectant and later dried. Mixing of Substrates and Spawning

Different combinations of substrates were prepared, as shown in Table 1. The plastic bottle was cut from the top, as shown in Fig. 1.
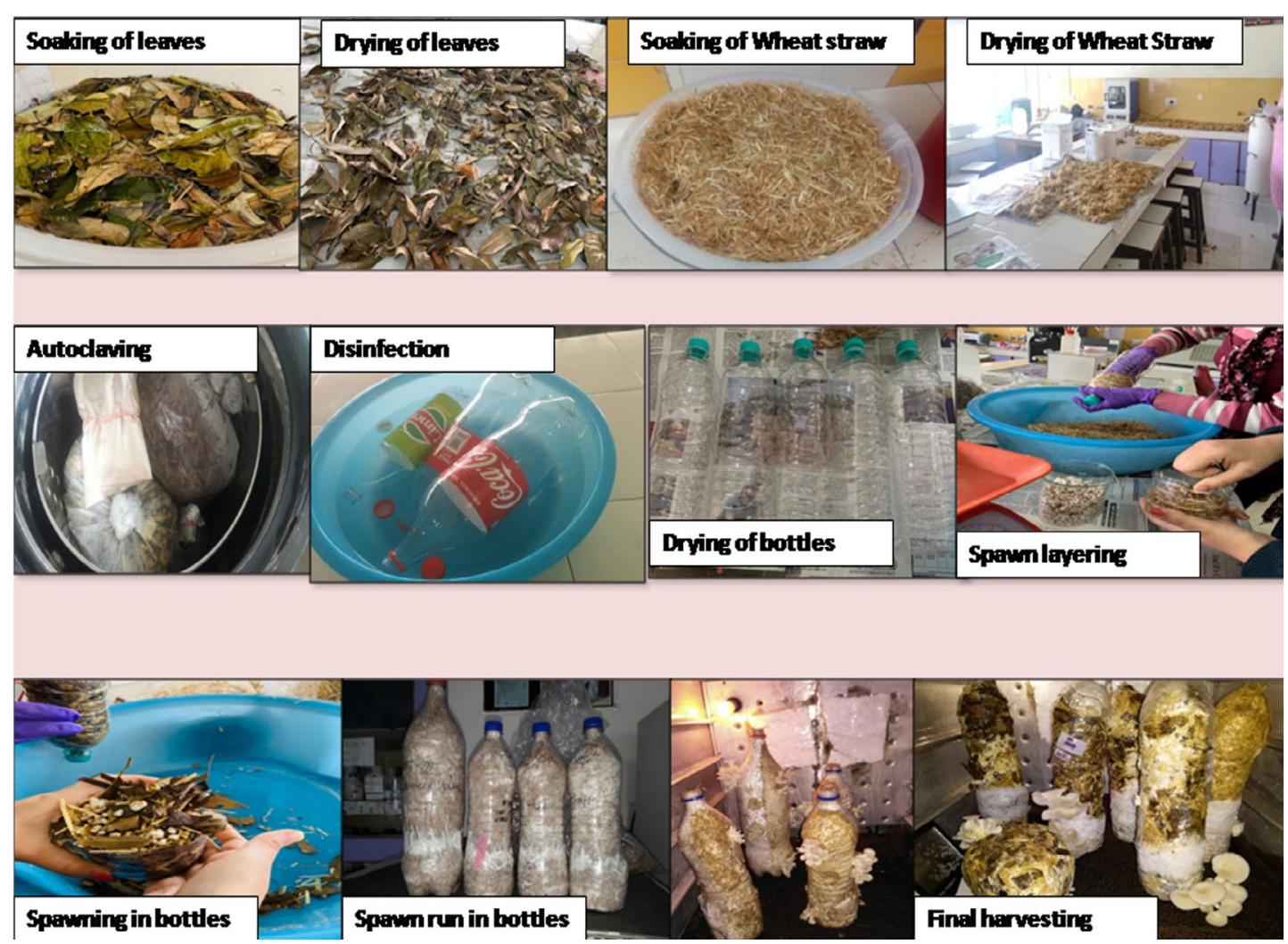

Fig. 1. Schematic representation of steps involved in the cultivation of Pleurotus ostreastus from agricultural and leaf waste in used plastic bottles. 
After mixing, the substrates were layered into the lower 3/4th portion of the Bisleri bottle $(500 \mathrm{ml})$, with each layer being approximately $5 \mathrm{~cm}$ thick. After each layer, one handful of spawn was evenly spread onto each layer. This way, the entire bottle was filled with 3-4 tightly packed layers. The upper portion of the cut bottle was also layered in the same way, and the two filled portions of the bottle were then tightly secured with brown tape. This was followed by piercing of 8-10 holes with sterile hole borer evenly spaced throughout the entire bottle. Three bottles for each combination were filled. The bottles were then incubated at $27^{\circ} \mathrm{C}$ in an incubator without light at a relative humidity of 65-75\%. During incubation, bottles were examined each day once for any mold contamination and observed the spawn run in different bottles for final scoring.

\section{Induction of Pinning and Final Harvesting}

When the inner substrate within the bottles got covered fully with white mycelial growth, large holes (5-6 cm wide) were bored aseptically within the plastic bottles. Pinhead initiation was obtained by decreasing the temperature by $5{ }^{\circ} \mathrm{C}$ and increasing the incubator chamber's humidity to $95 \%$. Light was allowed to enter the chamber for pinning to start. Bottles showing pinhead and primodia were carefully handled and sprayed thrice with distilled water to maintain high humidity. Fruiting bodies of $P$. ostreatus were finally harvested successively as they matured. Pinning and harvesting time for all

Table 2. Days took for complete mycelial colonisation, primordial formation, final harvesting, mean yield per bottle, and \% BE

\begin{tabular}{|c|c|c|c|c|c|}
\hline Bag No. & Combination & $\begin{array}{l}\text { Spawn Run } \\
\text { Time (days) }\end{array}$ & $\begin{array}{c}\text { Primordial } \\
\text { Formation (days) }\end{array}$ & $\begin{array}{l}\text { Final Harvest } \\
\text { Time (Days) }\end{array}$ & $\begin{array}{c}\% \mathrm{BE} \text { per } 450 \mathrm{~g} \\
\text { of substrate }\end{array}$ \\
\hline 1. & Only wheat (WS) & $16 \pm 0.5$ & $21 \pm 1$ & 26 & 62 \\
\hline 2. & Leaves + wheat straw & & & & \\
\hline 3. & $\begin{array}{c}\left(\mathrm{L}_{30}-\mathrm{WS}_{70}\right) \\
\text { Leaves }+ \text { wheat straw }\end{array}$ & $15 \pm 1$ & $21 \pm 0.5$ & 25 & 65 \\
\hline 4. & $\begin{array}{c}\left(\mathrm{L}_{50}-\mathrm{WS}_{50}\right) \\
\text { Leaves+ wheat straw }\end{array}$ & $17 \pm 1$ & $22 \pm 0.5$ & 28 & 58.1 \\
\hline & $\left(\mathrm{L}_{70}-\mathrm{WS}_{30}\right)$ & $20 \pm 1$ & $26 \pm 1.5$ & 31 & 42 \\
\hline 5. & Only leaves (L) & $23 \pm 0.5$ & $29 \pm 0.55$ & 35 & 16.5 \\
\hline
\end{tabular}

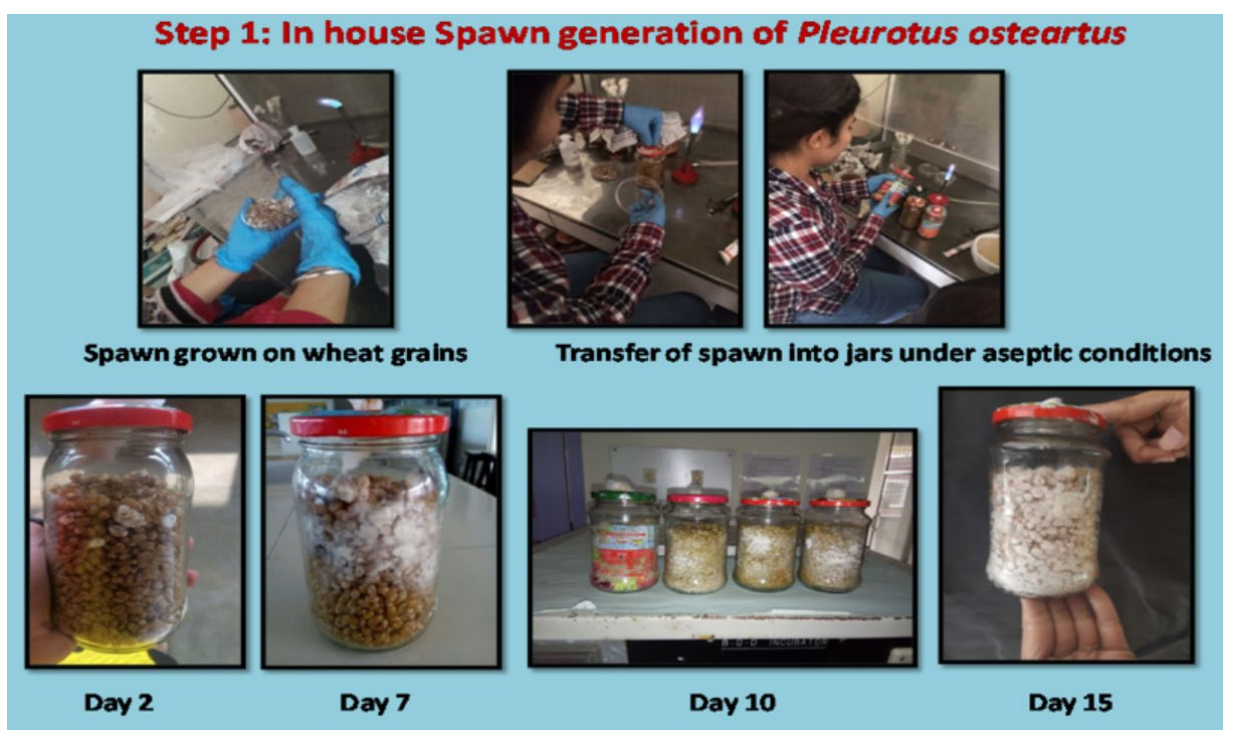

Fig. 2. In house spawn generation in glass jars on wheat grains 
the bottles was noted.

Biological Efficiency (yield)

Biological efficiency was determined to obtain the growth potential of the fungal strain. It was calculated by the following Eq. (1).

Biological efficiency $=$ weight of fresh mushroom/dry weight of substrate $\times 100 \%$

\section{Nutritional Analysis}

The mushrooms were checked for the following parameters:

(a) Total Ash Content: The ash content was calculated by applying the standard ash content method ${ }^{9}$. Clean and dry crucible was taken, and its weight was noted down. $5 \mathrm{~g}$ of mushroom was weighed and kept in the crucible. The weight of the crucible was noted
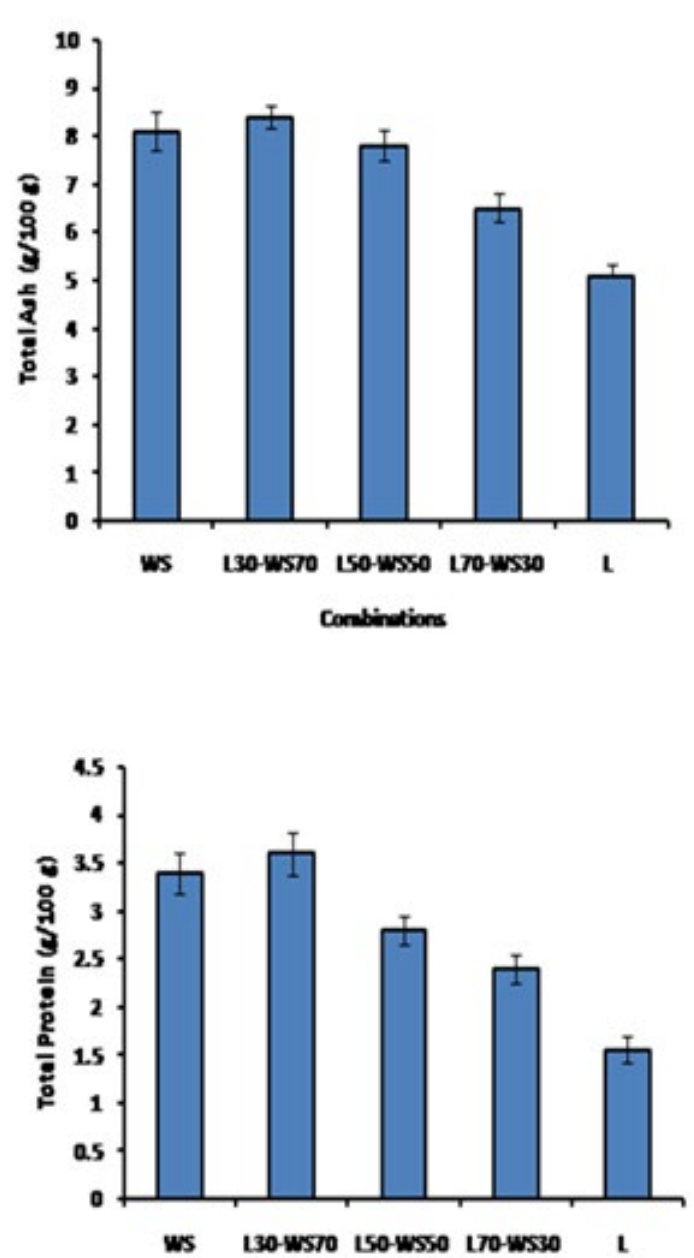

again with the sample. The sample was then charred until complete ash was formed. The sample was ignited at 550 oC for $1 \frac{1}{2} \mathrm{~h}$ in a muffle furnace. The sample was taken out from the muffle furnace, kept in a desiccator, and the weight was noted. Again, the sample was kept in a muffle furnace for $1 / 2 \mathrm{~h}$, removed, cooled in a desiccator and weight was noted down. This process was repeated till the difference between two consecutive readings was less than 0.1 and total ash calculated following Eq.2.

Total Ash content $=$ Weight of ash $* 100 /$ weight of the sample ...... Eq.(2)

(b) Protein content: $5 \mathrm{~g}$ of fresh mushroom was weighed and mixed with $50 \mathrm{ml}$ of sterile phosphate buffer. This was then subjected
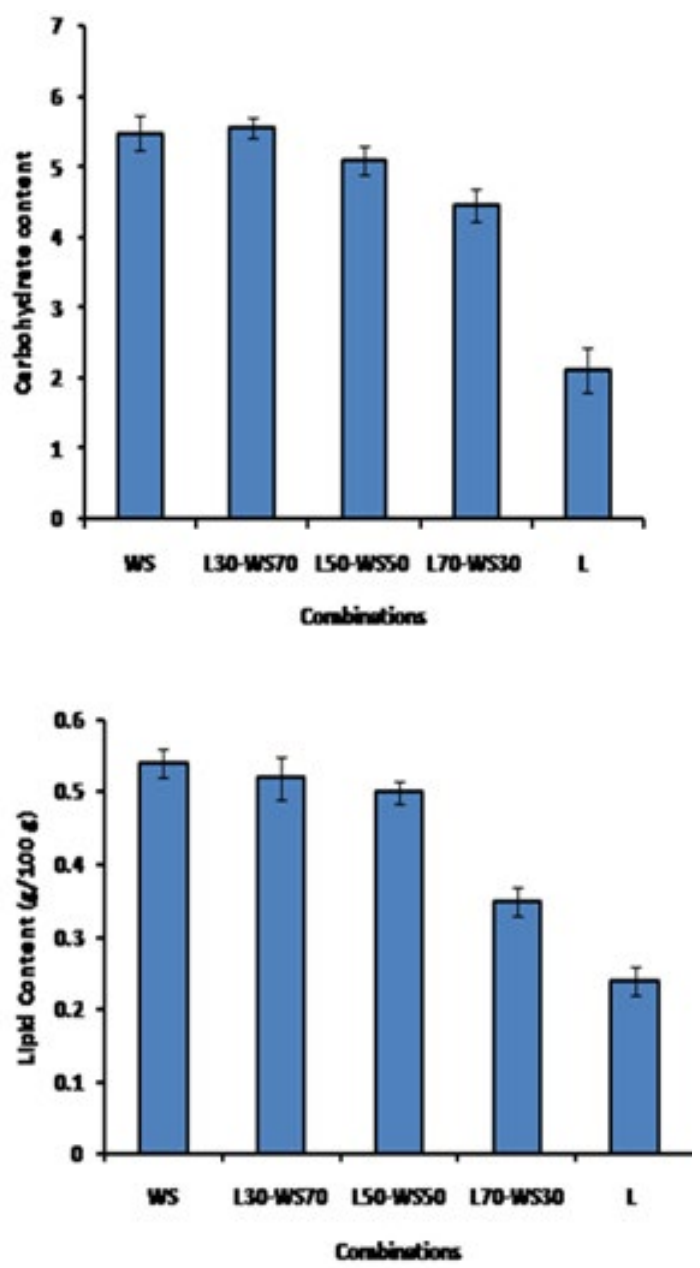

Fig. 3. Nutrient content of fresh mushrooms in different combinations ( $g$ of nutrient/100 g). 
to a manual homogeniser. The homogenised suspension was then centrifuged, and $5 \mathrm{ml}$ of supernatant was added to $50 \mathrm{ml}$ of 0.1 $\mathrm{N} \mathrm{NaOH}$. The sample was then subjected to protein content analysis as per the standard protocol of Lowry et al. ${ }^{10}$. The working solution was added to the test sample, incubated, and the absorbance was measured at $660 \mathrm{~nm}$. A standard curve using bovine serum albumin (BSA) was later plotted, and the protein content of the sample was calculated and expressed as $\mathrm{g} / 100 \mathrm{~g}$ of the fruit body sample.

(c) Total carbohydrate content: The total carbohydrate in the fruiting bodies was measured following the phenol-sulfuric acid $^{11}$. Briefly, the mushroom sample was homogenised as described above, and 0.05 $\mathrm{ml}(500 \mu \mathrm{l})$ of supernatant was taken and added to an equal volume of $5 \%$ phenol. To this mixture, $2 \mathrm{ml}$ of sulfuric acid was added and allowed to stand for $20 \mathrm{~min}$ at room temperature. The test was performed in duplicates and along with glucose as standard. Absorbance was measured at $470 \mathrm{~nm}$, and the total sugar calculated from the standard curve.

(d) Lipid Content: The total lipid levels were measured as per the standard method of Folch et al. ${ }^{12} .5 \mathrm{~g}$ of fresh mushroom was taken, sliced, added to $50 \mathrm{ml}$ mixture of chloroform: methanol(2:1) and mixed thoroughly. The preparation was covered airtight and allowed to stand for three days. Finally, the solution was centrifuged (1000 $\mathrm{g}, 10 \mathrm{~min}$ ), the upper layer of methanol was removed using Pasteur pipette, and crude lipid was collected and proceeded for the gravimetric analysis.

(Note: In addition to above, toxicity and BPA testing were also carried out as a safeguard to rule out the possibility of any toxicity and BPA leaching into the fruiting body and the raw data showed negative results).

\section{RESULTS}

\section{Oyster Spawn Production}

Potato Dextrose Agar was used to grow and maintain oyster mushroom culture procured from ICAR-Directorate of Mushroom Research, Solan, Himachal Pradesh. P. ostreatus was successfully grown on PDA. The oyster completely covered the media containing plate in 9 days with pure white cottony growth. Wheat grains of good quality were used for spawn production. It was mixed with $1 \%$ gypsum and exhibited a moisture content between $50-60 \%$. After inoculation, mycelium growth was initially slow for the first couple of days. Still, by the $5^{\text {th }}$ day, the growth was spread to more grains, and the cottony white growth of the mycelium started becoming visual throughout the glass jars (Fig. 2). Over time the cottony growth began to form web-like clusters in the grains, and the growth spread to the whole of the jar. By the $20^{\text {th }}$ day, the glass jars were completely covered with mycelium growth. These jars were ready with spawn for use in the subsequent experimentation studies. The jars were stored at $4{ }^{\circ} \mathrm{C}$ until further use.

\section{Mycelial Colonization in bottles (Spawn run)}

After spawning using 5\% spawn, all inoculated bottles exhibited mycelia extension standing from the spawn grains into the cultivation substrate after $24 \mathrm{~h}$ of spawning (Table 2). Mycelia extension throughout the substrates was varied among different substrate combinations. The minimum spawn run time was seen with WS bottles and $\mathrm{L}_{30}{ }^{-}$ $\mathrm{WS}_{70}$ combination as both showed a comparable average time of $16 \pm 0.5$ days for complete colonisation. With $\mathrm{L}_{50}-\mathrm{WS}_{50}$ combination, the spawn run time was slightly prolonged to $17 \pm 1$ days. However, with the $L_{70}-W_{30}$ combination, there was a significant increase in the total time for mycelia colonisation compared to WS bottles $(p<0.05)$, with the total time for spawn run being $20 \pm 1$ days. The least rate of mycelial colonisation was observed with the last combination of leaves only ( $L$ ) as it took the highest number of days ( $23 \pm 0.57$ days) (exhibited the lowest mycelial running rate) after inoculation of spawn. Also, the bottles with $L$ only showed asymmetric and poor spawn run seen in patches.

\section{Primordial formation and Final Harvesting Time (days of post Pinning)}

Similar to mycelial invasion, the initiation of pinning with the first primordial formation were different among different substrate combinations. In WS bottle and $\mathrm{L}_{30}-\mathrm{WS}_{70}$ combination, the first primordial appeared after $20 \pm 1$ days of spawn inoculation and for $\mathrm{L}_{50}-\mathrm{WS}_{50}$ combination $22 \pm 0.5$ days, respectively. The $L_{70}-W S_{30}$ combination 
took the highest number of days $(26 \pm 1.5)$ after spawning for primordial formation. The fruit body formation leading to final harvesting was done by day 25 (post spawn inoculation) and day 26 for $\mathrm{L}_{30^{-}}$ $\mathrm{WS}_{70}$ and WS bottles, and by day 28 for $\mathrm{L}_{50}-\mathrm{WS}_{50}$ bottle. However, the $\mathrm{L}_{70}-\mathrm{WS}_{30}$ combination showed a significantly longer time for a fruiting body's appearance with the final harvest at day 31 postspawn inoculation. The bottle packed with leaves only (L) showed very small pinheads on its surface with primordia's appearance at $29 \pm 0.5$ days and fruit body formation by day 35 .

\section{Biological Efficiency}

Mean Bioconversion efficiency (BE) per $450 \mathrm{~g}$ of bottles in different combinations has been depicted in Table 1. The maximum BE after 1st flush was calculated to be $65 \%$ for $\mathrm{L}_{30}-\mathrm{WS}_{70}$ and $62 \%$ for WS and $58.1 \%$ for $\mathrm{L}_{50}-\mathrm{WS}_{50}$. The $\mathrm{L}_{70^{-}}$ $\mathrm{WS}_{30}$ combination showed significantly low yield and $B E$ value (42\%) as compared to WS and $50-50$ combination $(p<0.05)$. However, the poor yield and lowest mean $B E$ value were obtained for $L$, only showing $B E$ of $16.5 \%$, indicating that leaves alone were unfavorable options for this mushrooms species.

\section{Nutritional Analysis}

Fresh mushrooms obtained from different combination bottles were subjected to nutritional analysis, as shown in Fig. 3. It was observed that mushrooms from both the WS bottles and $\mathrm{L}_{30}{ }^{-}$ $\mathrm{WS}_{70}$ combination bottles showed comparable nutritional parameters. The protein content was calculated to be $3.5 \mathrm{~g}$ per $100 \mathrm{~g}$, similar to the reported value. Mushroom being low in lipid content, showed a maximum lipid content of 0.54 g. With the $\mathrm{L}_{70}-\mathrm{WS}_{30}$ combination, mushrooms were of less nutritional value than other L-WS combinations in all four parameters. However, the poorest nutritional status was seen with mushrooms obtained out of leaves (L) bottles with protein being $1.56 \mathrm{~g}$ and carbohydrate and lipid levels being low, i.e. 2.12 and $0.24 \pm 0.02 \mathrm{~g}$ calculated.

\section{DISCUSSION}

Solid waste management has become a major cause of concern in developed and developing countries, stressing the need to adopt effective waste management strategies to reduce and recycle community waste and plastic waste.
The most effective way to address plastic pollution is to restrict its use or not create it in the first place. However, this is not a practical solution. The second solution is the reuse of plastic for various purposes, and this can significantly reduce the demand for new plastics, thus decreasing the overall usage ${ }^{13}$. Similarly, by utilising a mere $1 \%$ of agro-wastes towards mushroom production, India can produce a total of 3 million tonnes of mushroom ${ }^{14}$. The remarkable ability of edible fungi to use various substrates and transform complex organic compounds into simpler by-products can be put to use to covert and utilise the vast agricultural and green waste into the valuable and usable form ${ }^{15,16}$. With primary focus to reuse the plastic waste along with developing innovative strategy to put the green waste generated in our college to beneficial use, , the present study was planned to cultivate oyster mushrooms (Pleurotus ostreatus) in used plastic bottles of Coke, Pepsi, Bisleri from green and agro-waste based substrates..

Shredded wheat straw is one of the most common substrates used in practice to cultivate Pleurotus spp. Wheat straw is superior over other agro-waste in colonization rates and overall yield and productivity ${ }^{17-19}$. Therefore, wheat straw was taken as the base in our study in all the tested combinations. However, little work has been reported related to dry leaf waste as a potential substrate in the past. Shah et al. ${ }^{20}$ also studied various combinations of wheat straw and saw dust and leaves for the cultivation of Pleurotus ostreatus but did not mention the exact source and type of leaves used. Alananbeh et al. ${ }^{21}$ studied the potential of date palm leaves along with wheat straw for cultivation purposes. Sharmila et al. ${ }^{22}$ studied the use of Areca palm leaves mixed with topsoil as the possible substrate for Pleurotus spp. These workers have primarily focussed on only one kind of leaf residues to cultivate different species of Oyster mushrooms. Balasubramani et al. ${ }^{23}$ reported a study using dried forest leaf litter from Teak, Bamboo, Populus, Eucalyptus to integrate oyster mushroom into the agroforestry model to generate proteinaceous food for the rural community. In the present study, we have reported the use of dried leaf litter (fallen and collected from college campus), which represents a mixture of leaves of five very commonly planted species of 
trees (Eucalyptus, Teak, Pinus, Chuksaria, Alfstonia) mixed with wheat straw in used plastic bottles. This unique initiative represents an ideal model for recycling agro-waste and fallen leaf waste (highly prevalent as seen in community parks, gardens, side of city roads) as a major disposal issue by local $\mathrm{MC}$ along with plastic re-use.

Different substrate combinations of wheat straw (representing agricultural waste/ by-product) and dried leaves were taken and used for bottle filling and spawning. Spawn run is a crucial stage and indicates the growth medium's suitability for the fungal species involved. Depending on the fungal strain used, growth conditions are given, and the substrate type, a variation in the time required for complete mycelia runs over the used substrate ${ }^{24}$. The minimum spawn run time ( 15 days) was seen with $\mathrm{L}_{30}-\mathrm{WS}_{70}$ among all the combinations, and this was comparable with WS control bottles. Following complete colonisation over the substrate, pinhead formation (primordium initiation) occurs. The time required to form pinheads in the present study (21-27 days of post-spawning) is comparable with past studies. Ahmed ${ }^{25}$ reported 23-27 days from spawning required for pinhead formation of oyster mushroom cultivated using different substrates, while Fan et al. ${ }^{26}$ reported this period to last from 20 to 23 days. It was observed that with an increase in the concentration of leaf residues, the spawn run time followed by the appearance of primordia lengthened. Poor growth of mycelium was seen in bottles filled with leaves only.

Adetola et al. ${ }^{27}$ did a comparative analysis of withered leaf mineral composition of teak, indicated that they are a very good source of calcium, magnesium, sodium, phosphorous, iron and potassium etc. Similarly, past studies reported that even dried leaves of Pinus and Eucalyptus act as a source of important minerals (Ca, N, P. K, $\mathrm{Mg})^{28,29}$. According to $\mathrm{Oei}^{30}$, mushroom mycelia growth is promoted better by adding supplements that provide a ready source of essential nutrients. In our study, the leaf residues mixed at a ratio of 30:70 and even 50:50 acted as a source of important nutrients, thus boosting the spawn run and giving the highest yield and \% BE. However, the noticeable feature is that as the concentration of leaf residues increased, i.e. in 70:30 and especially in $100 \%$ leaf bottles, there was a negative impact on all the growth parameters with poor yield. Workers in the past have extensively reported the antimicrobial and antifungal activity of the leaf extracts of Eucalyptus ${ }^{31-33}$ and Pinus ${ }^{34}$. Also various Teak species (e.g. Tectona grandis) are antimicrobial and antifungal ${ }^{35-37}$. This clearly explains the comparatively higher time for spawn run (20-21 days), longer time for pinhead and primordia appearance with poor yield, and significantly low BE of $42 \%$ in bottles with combinations at $\mathrm{L}_{70}: \mathrm{WS}_{30}$. The bottles with the highest leaf concentration were not a suitable medium, as all the values of parameters were significantly lower $(P<0.05)$ compared to the control combination.

One of our country's prime issues is poor health and nutrition among the underprivileged population. The FAO has strongly recommended the intake of edible mushroom varieties in a routine diet, representing a protein nutrition source, especially in developing countries ${ }^{38,39}$. The mushrooms obtained from $\mathrm{L}_{30}: \mathrm{WS}_{70}$ and $\mathrm{L}_{50}: \mathrm{WS}_{50}$ bottles were high in protein content (3.5 g per $100 \mathrm{~g})$, similar to that earlier reported ${ }^{40-42}$. The mushrooms showed a low lipid content, thus representing an ideal choice for the target population (obese people, diabetics, pregnant, etc. $)^{43-45}$. One of the possible issues associated with using plastic bottles of Bisleri and Coke may arise from the leaching of BPA. BPA stands for Bisphenol $A$, a common building block in resins and some plastic types. It is a known compound that is endocrine-disrupting ${ }^{46,47}$. However, BPA is found in only certain types of plastic called polycarbonate. In contrast, the bottled water and plastic soft drink bottles are made from Polyethylene Tetraphthalate (PET), which has nothing to do with BPA. Also, as per the American Chemistry Council (ACC) and International Life Sciences Institute (ILSI), PET has been approved and regarded as safe for use ${ }^{48}$. Moreover, the bottles used in the present study are graded as $\neq 1$, which, according to Eartheasy. com, are the safest choice as being free from BPA and are $100 \%$ recyclable ${ }^{49}$. Also, the raw data about toxicity and BPA leaching were negative in all the tested combinations.

\section{CONCLUSION}

The present study has highlighted the cultivation of Oyster mushroom in used plastic 
bottles as a community waste management model integrating agricultural waste and dried fallen leaf litter (fallen and collected from community parks, gardens, side of city roads) as potential substrates for the generation of protein-rich food for the target population (the rich and the poor) while putting the plastic trash to beneficial re-use. Both the combinations of 30:70 and 50:50 represented ideal options for using the two waste substrates. It proved to be better in terms of mycelial run's total time, primodia formation, development of fruiting bodies, and final mushroom harvesting. However, the practical use of this model to solve the issues of fallen leaf litter and agricultural byproduct burning has to be taken to the next level by promoting the concept to the local government bodies and creating awareness among the masses as well.

\section{ACKNOWLEDGMENTS}

The assistance provided by the Department of Food Science and Mehr Chand Mahajan DAV College for Women, Chandigarh, is gratefully acknowledged.

\section{CONFLICT OF INTEREST}

The authors declare that there is no conflict of interest.

\section{AUTHORS' CONTRIBUTION}

All authors designed the experiments. SK, HB, BH, BA, NK, NS, VS performed the experiments and analysed the data. SK, VS wrote the manuscript.All authors read and approved the manuscript.

\section{FUNDING}

None.

\section{DATA AVAILABILITY}

All datasets generated or analyzed during this study are included in the manuscript

\section{ETHICS STATEMENT}

This article does not contain any studies with human participants or animals performed by any of the authors.

\section{REFERENCES}

1. Center for EcoTechnology. Climate Change, Recycling, Sustainability, Waste Diversion, Zero Waste. 2017. https://www.centerforecotechnology.org/plasticpollution/

2. Cusworth DH, Mickley LJ, Sulprizio MP, et al. Quantifying the Influence of Agricultural Fires in Northwest India on Urban Air Pollution in Delhi, India. Environ Res Lett. 2018;13(4):044018. doi: 10.1088/1748-9326/aab303

3. Down to Earth. Crop Burning: Punjab and Haryana's killer fields. 2016. https://www.downtoearth.org. in/news/air/crop-burning-punjab-haryana-s-killerfields-55960

4. Bhave PP, Sadhwani K. Solid Waste Management Legislation - A Review. Environmental Policy and Law. 2016;46(2):165-190. doi: 10.3233/EPL-46205

5. Ananbeh KM. Production of oyster mushroom on different agricultural wastes available in Jordan. $M$. Sc. Thesis, Jordan University, Jordan. 2003.

6. Stamets P. Notes on nutritional properties of culinarymedicinal mushrooms. Int J Med Mushrooms. 2005;7(3):103-110. doi: 15/IntJMedMushr.v7.i12.100

7. Roupas P, Keogh J, Noakes M, Margetts C, Taylor P. The role of edible mushrooms in health: evaluation of the evidence. J Funct Foods. 2012;4(4):687-709. doi: 10.1016/j.jff.2012.05.003

8. Deepalakshmi K, Mirunalini S. Pleurotus ostreatus: an oyster mushroom with nutritional and medicinal properties. J Biochem Tech. 2014;5(2):718-726.

9. Raghuramulu N, Madhavan NK, Kalyanasundaram S. A Manual of Laboratory Techniques, National Institute of Nutrition. Indian Council of Medical Research, Hyderabad, India. 2003.

10. Lowry $\mathrm{OH}$, Rosebrough NJ, Farr AL, Randall RJ. Protein measurement with Folin phenol reagent. J Biol Chem. 1951;193:265-275. doi: 10.1016/S00219258(19)52451-6

11. Dubois M, Gilles KA, Hamilton JK, Rebers PA, Smith F. Colorimetric method for determination of sugars and related substances. Anal Chem. 1956;28(3):350-356. doi: 10.1021/ac60111a017

12. Folch J, Lees M, Sloane-Stanley GH. A simple method for the isolation and purification of total lipids from animal tissue. J Biol Chem. 1957;226(1):497-509. doi: 10.1016/S0021-9258(18)64849-5

13. Improving Plastics Management: Trends, policy responses, and the role of international co-operation and trade OECD environment policy paper no. 12 . 2018.

14. Chitra K, Venkatesh R, Dhanalakshmi K, Sharavanan PT, Sasikumar CB, Vijayakumari KK. Production and Economic Analysis of Oyster Mushroom (Pleurotus florida). Int J Curr Microbiol App Sci. 2018;7(9):379383. doi: 10.20546/ijcmas.2018.709.046

15. Jain AK, Vyas D. Yield response of $P$. florida on wheat straw in combination with other substrates. Mush Res. 2002;11:19-20. 
16. Kamthan R, Tiwari I. Agricultural wastes - Potential substrates for mushroom cultivation. Eur Exp Biol. 2017;7(5):31. doi: 10.21767/2248-9215.100031

17. Philippoussis A, Zervakis G, Diamantopoulou P. Bioconversion of agricultural lignocellulosic wastes through the cultivation of the edible mushrooms Agrocybe aegerita, Volvariella volvacea and Pleurotus spp. World J Microbiol Biotechnol. 2001;17:191-200. doi: 10.1023/A:1016685530312

18. Pant D, Reddy UG, Adholeya A. Cultivation of oyster mushrooms on wheat straw and bagasse substrate amended with distillery effluent. World J Microbiol Biotechnol. 2006;22:267-275. doi: 10.1007/s11274005-9031-2

19. Fanadzo M, Zireva DT, Dube E, Mashingaidze AB. Evaluation of various substrates and supplements for biological efficiency of Pleurotus sajor-caju and Pleurotus ostreatus. Afr J Biotechnol. 2010;9(19):27562761. doi: 10.5897/AJB09.1259

20. Shah ZA, Ashraf M, Ishtia M. Comparative study on cultivation and yield performance of oyster mushroom (Pleurotus ostreatus) on different substrates (wheat straw, leaves, saw dust). Pak J Nut. 2004;3(3):158-160. doi: 10.3923/pjn.2004.158.160

21. Alananbeh KM, Bouqellah NA, Al Kaff NS. Cultivation of oyster mushroom Pleurotus ostreatus on date-palm leaves mixed with other agro-wastes in Saudi Arabia. Saudi J Biol Sci. 2014;21(6):616-625. doi: 10.1016/j. sjbs.2014.08.001

22. Sharmila S, Rebecca LJ, Tissopi T, Kowsalya E. Effect of substrates on the cultivation of Pleurotus ostreatus and its nutritional analysis. Der Pharmacia Lettre. 2015;7(8):193-196.

23. Balasubramani N, Poovendhan M, Thiribhuvanamala G, Tilak M, Revathi R, Parthiban KT. Bioconversion of Agro Forest Residues for Production of Oyster Mushrooms. Int J Environ Agric Biotech. 2017;2(5):2659-2666.

24. Chang S, Miles, GP. Mushrooms: Cultivation, Nutritional Value, Medicinal Effects and Environmental Impact. 2004:436. Boca Raton, FL: CRC Press. doi: 10.1201/9780203492086

25. Ahmed S. Development of mushroom varieties suitable for rural level in Bangladesh. Report presented in BARC Annual Review Programme. 1998;72-73.

26. Fan L, Pandey A, Mohan R, Soccol CR. Use of various coffee industry residues for the cultivation of Pleurotus ostreatus in solid state fermentation. Acta Biotechnol. 2000;20(1):41-52. doi: 10.1002/abio.370200108

27. Adetola OO. Comparative analysis of mineral elements of green and withered brown leaves of Tectona grandis Linn in Nigeria. World Scientific News. 2019;128(2):426-432.

28. Poggiani F. Nutrient cycling in Eucalyptus and Pinus plantations ecosystems, silvicultural implications. Instituto de Pesquisas e Estudos Florestais. 1985;3:33-40.

29. Barry KM, Janos DP, Nichols S, Bowman DM. Eucalyptus obliqua seedling growth in organic vs. mineral soil horizons. Front Plant Sci. 2015;20;6:97. doi: 10.3389/ fpls.2015.00097.
30. Oei P. Mushroom cultivation with special emphasis on appropriate techniques for developing countries. Tool Publications, Leiden. 1996:274.

31. Musyimi DM, Muema O, Muema PM. Phytochemical compounds and antimicrobial activity of extracts of aspilia plant (Aspiliam ossambicensis) (Oliv) Wild. Int J Bot. 2008;4(1):56-61. doi: 10.3923/ijb.2008.56.61

32. Tiwari R, Singh SK, Choudhury S, Garg, SK. Antifungal Activity of Methanolic Extracts of Leaves of Eucalyptus citriodora and Saraca indica Against Fungal Isolates from Dermatological Disorders in Canines. Int $J$ Pharmacol. 2017;13(6):643-648. doi: 10.3923/ ijp.2017.643.648.

33. Kaur S, Sharma N, Aanchal, et al. Anti-biofilm potential of aqueous Eucalyptus leaf extract against nosocomial pathogens: Staphylococcus and Pseudomonas aeruginosa. The Pharma Innovation Journal. 2018;7(11):425-432.

34. Czerwinska E, Szparaga A. Antibacterial and antifungal activity of plant extracts. Rocznik Ochrona Srodowiska. 2015; 17:209-229.

35. Gupta KP, Singh P. A naphthoquinone derivative from Tectonagrandis Linn.J Asian NatProd Res. 2004;6(3):237240. doi: 10.1080/10286020310001653192

36. Astiti NPA, Suprapta DN. Antifungal activity of teak (Tectona grandis L.f) leaf extract against Arthrinium Phaeospermum (Corda) m.b. ellis, the cause of wood decay on Albizia Falcataria (L.) fosberg. J Int Soc Southeast Asian Agr Sci. 2012;18(1):62-69.

37. Lukmandaru G. Antifungal activities of certain components of teak wood extractives. J Trop Wood Sci Technol. 2013;11:11-18.

38. Raut JK. Current Status, Challenges and Prospects of Mushroom Industry in Nepal. Int J Agr Eco. 2019;4(4):154-160. doi: 10.11648/j.ijae.20190404.13

39. Nagaraj R, Arun KP, Hanumanthaswamy BC, Jyoti MR. Mushroom Production for Self Employment - An Impact Study. Int J Curr Microbiol App Sci. 2017;6(9):29912997. doi: 10.20546/ijcmas.2017.609.367

40. Alam N, Amin R, Khan A, et al. Nutritional analysis of cultivated mushrooms in Bangladesh: Pleurotus ostreatus, Pleurotus sajor-caju, Pleurotus florida and Calocybe indica. Mycobiology. 2008;36(4):228-232. doi: 10.4489/MYCO.2008.36.4.228.

41. Daba AS, Kabeil SS, Botros WA, El-Saadani MA. Production of mushroom (Pleurotus ostreatus) in Egypt as a source of nutritional and medicinal food. WJAS. 2008;4(5):630-634.

42. Patil SS, Kadam RM, Shinde SI, Deshmukh SA. Effect of different substrates on productivity and proximate composition of Pleurotus florida. Int J Plant Sci. 2008;3(1):151-153.

43. Alam N, Amin R, Khan A, et al. Comparative effects of oyster mushrooms on lipid profile, liver and kidney function in hypercholesterolemic rats. Mycobiology. 2009;37(1):37-42. doi: 10.4489/MYC0.2009.37.1.037

44. Schneider I, Kressel G, Meyer A, Krings U, Berger RG, Hahn A. Lipid lowering effects of oyster mushroom (Pleurotus ostreatus) in humans. J Func Foods. 2011;3(1):17-24. doi: 10.1016/j.jff.2010.11.004 
45. Valverde ME, Hernandez-Perez T, ParedesLopez O. Edible mushrooms: Improving human health and promoting quality life. Int J Microbiol. 2015;2015:376387.doi: 10.1155/2015/376387

46. Rubin BS. Bisphenol A: an endocrine disruptor with widespread exposure and multiple effects. J Steroid Biochem Mol Biol. 2011;127(1-2):27-34. doi: 10.1016/j. jsbmb.2011.05.002
47. Talpade J, Shrman K, Sharma RK, Gutham V, Singh RP, Meena NS. Bisphenol a: An endocrine disruptor. J Entomol Zool Stud. 2018;6(3): 394-397.

48. ILSI-India Conference on India Conference on Food Safety and Security. PET \& other Plastic Containers: Industry Overview and Innovative Solutions for Food Packaging. 2017.

49. Eartheasy. Plastics by the Numbers. 2012. https://learn. eartheasy.com/articles/plastics-by-the-numbers/ 